\title{
Philosophical SCRutiny Provides a Fresh Perspective On Cultural Evolution
}

\author{
Christine A. Caldwell \\ Division of Psychology, University of Stirling, Stirling, United Kingdom. \\ c.a.caldwell@stir.ac.uk
}

A Review of the Book

Cultural Evolution

By Tim Lewens. 2015.

Oxford University Press, Oxford, 205 pages.

ISBN 978-0-19-967418-3 (Hardback, US\$45.00)

Tim Lewens' book provides a valuable outsider's perspective on the field of cultural evolution. Lewens, a philosopher, has no horse in the race as regards the big debates that have defined, and sometimes divided, this burgeoning academic subdiscipline. Thus, he is well placed to evaluate the relative merits of competing arguments, and to judge whether any limitations inherent to the field's approaches are tolerable in light of the concomitant contributions to understanding.

Happily, at least speaking from the perspective of someone who was been working in this field for some years now, his general conclusions would appear to be very positive for research in cultural evolution. To summarise my understanding in extremely brief form, Lewens's main messages seem to be these: firstly, in spite of the big debates ongoing within cultural evolution, the field can make valuable progress regardless of these issues remaining unresolved; and secondly, whilst there are undeniable limitations inherent in the cultural evolutionary framework, these are not fatal, and the field's central concepts and tools have considerable explanatory power nonetheless.

The volume is pleasingly succinct and very readable, and yet it provides a comprehensive overview of several of the key critical theoretical issues which have preoccupied those with an interest in this field. As such it would provide an extremely worthwhile introduction to the field for a relative newcomer - graduate students perhaps, 
or researchers from other disciplinary areas. For those already working on topics related to cultural evolution, much of the content will seem familiar, but it remains enlightening to see how these debates appear through the analytical lens of Lewens's philosophical perspective.

The book begins, entirely appropriately, with one of the biggest debates of them all, addressing the issue of whether cultural evolution can be accurately characterised as a Darwinian selective process. Lewens tells us that cultural change may well not occur via struggle for survival between competing traits, and so is probably not a case of evolution in this strict Darwinian sense. However, he also tells us that this does not matter, and that acknowledging this does not reduce us to accepting an entirely banal, and analytically weak, conceptualisation of cultural evolution, which maintains only that culture does change incrementally over time.

Lewens goes so far as to provide a label for those of us who subscribe to a view of culture that is not heavily committed to a role for selective processes, but who also find value in formal models of population-level phenomena as a means of testing and generating predictions. Those in this camp are "kinetic theorists", likening this perspective to the kinetic theory of gases, which generates predictions regarding higherorder levels of description (temperature, pressure) from what is known about constituent individual elements (atoms, molecules). Thus, Lewens perceives no problematic logical contradiction in a cultural evolutionary research programme that wishes to exploit the tools of evolutionary biology, without committing to a strong analogy between cultural and genetic evolution. We are not simply demanding to both have our cake and eat it; we are "kinetic theorists". I suspect this term will catch on.

Lewens goes on to knock down other criticisms of the cultural evolutionary research programme, including the charge that the very notion of gene-culture coevolution requires us to assume an artificially dichotomous distinction between the biological and the cultural. He also deftly argues against the accusation that there is little insight to be gained from pared-down, formalised models of something as messy, slippery and complex as human culture. These sections were interesting to me, but I have to confess that these were not concerns that had ever kept me awake at night in any case. So although it was again reassuring to know that an inquiring philosophical mind had arrived at similar opinions to my own (and likely after a good deal more explicit consideration), these parts of the book had less impact for me.

In contrast, I found the analysis offered in Lewens's penultimate chapter enlightening as well as incisive. This section considered the differences (and perhaps more interestingly, the deep similarities) between the views expressed by those who place themselves in the cultural evolutionary camp, and the slightly more ill-defined group of researchers generally ascribed the collective label of "the Santa Barbara school". I found it hugely refreshing to read an account of these views which drew attention to the commonalities between them, which are actually rather profound. Lewens conveys this very effectively, whilst still being clear about precisely what the key differences are.

It would be flippant to conclude that the take home message boils down to simply: "Carry on, cultural evolutionists. All is well." There is far more to the book than this, including highlighting potential stumbling blocks for the field, and suggestions for promising future avenues of investigation. However, it is clear that from Tim Lewens's standpoint, the future looks bright for cultural evolutionary research. I expect that for 
those working in the field, this could prove to be an extremely valuable key reference for defending some of our key assumptions, methods, and conclusions.

\section{ABOUT THE AUTHOR}

Christine A. Caldwell is a researcher with interests in social learning and cultural traditions in humans and nonhuman primates. She uses experimental methods to study cultural evolution, and related phenomena, under laboratory conditions. 